\title{
Turismo Rural, Empreendedorismo e Gênero: um estudo de caso na comunidade autônoma da Galiza
}

\author{
$M^{\underline{a}}$ Isabel Dieguez-Castrillon ${ }^{1}$, Ana Gueimonde-Canto ${ }^{2}$, \\ Ana Sinde-Cantorna ${ }^{3}$ e Lidia Blanco-Cerradelo ${ }^{4}$
}

\begin{abstract}
Resumo: Neste trabalhoindagamos sobre possíveis diferenças no comportamento empreendedor em turismo rural; estabelecemos características e dimensões motivadoras em função do gênero. Num exemplo representativo de estabelecimentos de turismo rural da Comunidade Autônoma da Galiza (Espanha), encontramos relação entre gênero e importância da compatibilização de atividades agrárias e tumrísticas, e entre gênero e perfil das motivações para empreender atividades de turismo rural. As mulheres estão mais motivadas por elementos do âmbito econômico e, portanto, na tomada de decisões, têm mais relevância os critérios de racionalidade econômica unidos à estratégia de diversificação da atividade agrária em favor da sobrevivência financeira. Ao contrário do estabelecido na maior parte da literatura, os fatores de índole social, familiar ou institucional têm a mesma importância para homens e mulheres. Aliás, verifica-se a ausência de relação entre gênero e características pessoais (como idade e formação e necessidades financeiras do empreendedor).
\end{abstract}

Palavras-chaves: gênero, motivação, turismo rural, empreendedorismo, diversificação.

\begin{abstract}
In this paper we establish entrepreneurship characteristics and motivational dimension by gender. Analyzing a representative sample of rural tourism establishments of the Autonomous Community of Galicia (Spain), we seek behavioural differences between gender holders. Relationship is found between gender and reconciliation and importance of agricultural activities by owner, and between gender and profile of the motivations to start tourism activity. Female entrepreneurs are more motivated by elements in the economic sphere and, therefore, have a greater role in decision-making rational economic criteria and diversification of agriculture.
\end{abstract}

Key-words: gender, motivations, rural tourism, entrepreneurship, diversification.

Classificação JEL: L83, M13.

\footnotetext{
1 Professora da Universidade de Vigo. E-mail: idieguez@uvigo.es.

2 Professora da Universidade de Vigo. E-mail: agueimonde@uvigo.es.

3 Professora da Universidade de Vigo. E-mail: asinde@uvigo.es.

4 Pesquisadora da Universidade de Vigo. E-mail: lyblanco@uvigo.es.
} 


\section{Introdução}

Nos últimos anos, as políticas de desenvolvimento rural na Europa estão centradas na criação de um modelo de rural destinado a desempenhar novas funções. Estas políticas vão dirigidas a afiançar a manutenção e conservação das paisagens e a retenção da população rural, integrando harmonicamente o conjunto do território. Nessa linha, os eixos sobre os quais se apoiam as medidas de desenvolvimento rural na Galícia concentram-se na valorização do património cultural e na diversificação de atividades econômicas, entre as quais se encontra o turismo.

Durante os últimos anos coexistem dois fenômenos no âmbito rural: por um lado, a execução de novas propostas e medidas de desenvolvimento e reestruturação rural e, por outro, a incorporação das mulheres ao âmbito econômico, social e laboral. O papel tradicional da mulher no rural estava associado fundamentalmente às explorações agrárias e às atividades artesanais, em grande medida relizadas no lar e em benefício dele, sem vinculação direta a compensações e rendimentos, com horários totalmente flexíveis, e compatibilizados com o trabalho doméstico. No quadro da reestruturação econômica, da diversificação das rendas familiares e do desenvolvimento rural, aparecem novas atividades como o turismo rural além de se gerar o processo de incorporação das mulheres às mesmas.

Na literatura encontramos diferentes opiniões em relação à motivação para começar atividades empresariais. Alguns autores mantêm que não existem diferenças patentes entre os motivos em função do gênero (VERHEUL et al., 2004), enquanto outros defendem motivações diferentes (BODEN e NUNCI, 2000; MARLOW et al. 2009; WATSON e ROBINSON, 2003).

O objetivo do presente estudo é pesquisar sobre o comportamento empreendedor e a decisão de diversificar atividades para o turismo rural em função do gênero.

No âmbito do turismo não existe suficiente pesquisa científica (BIGNÉ, 1996; ANTÓN et al., 1996; FIGUEROLA, 2000; ESTEBAN, 2000), e a publicada apresenta fundamentalmente um perfil de marketing, geografia ou economia aplicada, sem existirem trabalhos determinantes na focagem da direção de empresas. Os estudos realizados até agora que tratam o tema do gênero no setor do turismo rural na Espanha, são generalistas e descritivos sobre o papel da mulher no turismo rural numa perspectiva quer geográfica (SPARRER, 2003; SPARRER, 2005; CABALLÉ, 1999; CANOVES e VILLARINO, 2002; GARCÍA RAMÓN et al., 1995), quer sociológica (SAMPEDRO e CAMARERO, 2007). Nenhum deles analisa as motivações para empreender atividades no turismo rural seja qual for o gênero. Alguns trabalhos que tratam a questão nos meios rurais europeus e americanos concretos, como os de McGehee et al. (2007); Iakovidou et al. (2009) ou Robinson (2001), permitem situar a problemática e fixar as bases para aprofundar sobre o comportamento empreendedor e sobre o gênero no contexto determinado do turismo rural. Porém, todos eles manifestam a necessidade de continuar a pesquisar. Os resultados da pesquisa 
permitiriam o avanço na análise dos elementos determinantes da diversificação agrária e nos elementos que influenciam o comportamento empreendedor.

$\mathrm{O}$ trabalho divide-se em cinco seções. $\mathrm{Na}$ segunda, revisa-se, respectivamente, a literatura que aborda a presença da mulher no mundo empresarial e as motivações para empreender atividades de turismo rural ligadas estreitamente à diversificação agrária. São justificadas, além disso, as hipóteses da pesquisa. Na terceira seção trata-se a metodologia utilizada na pesquisa, o modelo e recolha de informação. Na quarta expõem-se e comentam-se os principais resultados e o contraste das hipóteses. Por último, são apresentadas ilações, limitações, futuras linhas de pesquisa e possíveis melhoras.

\section{Fundamentação teórica}

\subsection{A realidade da mulher no turismo rural}

No momento atual avança-se na superação da divisão do trabalho característica das sociedades agrárias, com as mulheres na esfera privada, longe do âmbito público. Tradicionalmente, as atividades das mulheres são circunscritas ao âmbito da família, e o papel da mulher na vida social, política, econômica e comunitária é invisibilizado e desvalorizado. Todavia, as mulheres das áreas sempre desempenharam um papel fundamental no desenvolvimento das suas comunidades, com um papel muito ativo, embora não reconhecida na economia (IAKOVIDOU et al., 2009; LITTLE, 1987).

A associação da mulher ao trabalho doméstico ou reprodutivo nasce, segundo Brullet (2004), com o ideal burguês da figura da "dona do lar", modelo que na segunda parte do século $X X$ vira hegemônico. Considerava-se que o papel da boa "mãe" consistia na criança dos filhos e o cuidado do lar. Esta exclusão das mães do trabalho remunerado supõe exclusão delas do âmbito produtivo.

Comodecorrer do tempoavança-se do trabalho reprodutivo ao trabalho produtivo. Contudo, as mudanças que propiciam a incorporação da mulher fora do âmbito doméstico, privado e familiar, podem ser difíceis. Assim, segundo diversos estudos realizados, as mulheres tendem a concentrar-se em atividades que são compatíveis com a reprodução e com o cuidado das crianças e são consideradas uma extensão das atividades domésticas, têm caráter pouco permanente e baixa remuneração, sendo consideradas como subordinadas ao trabalho do homem (MARLOW e STRANGE, 1994; LITTLE, 1987).

No mercado de trabalho rural, tradicionalmente as mulheres apareciam invisibilizadas, apesar de realizarem uma tarefa importante, os titulares e proprietários das explorações agrárias sempre eram os homens, os quais, em muitos casos, desempenham atividades também fora da exploração.

Os dados sobre a participação das mulheres nos programas comunitários Leader II e Proder (MARTÍNEZ, 2007), revelam que, no estado espanhol, um terço das iniciativas foram realizados por mulheres $(34,68 \%)$. Os dados para a Comunidade Autônoma da Galiza estabelecem uma percentagem de $36,22 \%$ de projetos apresentados por mulheres, tendo relação com o âmbito do turismo rural 52,6\% dos projetos aprovados e $65 \%$ do investimento.

No final de 2008, as mulheres representavam $71,21 \%$ do emprego do setor. É uma percentagem muito superior à taxa galega de ocupação feminina global e à do setor terciário (serviços), que, nessa mesma data, era de $44,8 \%$ e de $56 \%$, respectivamente.

Os dados assinalados revelam a importante dimensão quantitativa do fenômeno. No entanto, no âmbito empresarial as mulheres conformam somente 30\% do empresariado, quer na Espanha, quer em países como Canadá, Dinamarca, Finlândia e Nova Zelândia (BRUSH et al., 2006). Aliás, a taxa de iniciativa empresarial feminina espanhola ocupa a posição 21 , fato pelo qual se demonstra a importância de uma ajuda à mulher empreendedora espanhola para atingir a paridade (Relatório GEM-2003), enquanto nalgum setor específico como o turismo rural a ajuda é desnecessária, pois o avanço para essa 
paridade é rápido. É por isso que consideramos importante analisar o acontecido neste âmbito para determinar os fatores influentes neste comportamento diferenciado.

\subsection{Investigações sobre gênero, empresa e turismo rural}

Para a renovação do tecido social e econômico e o envolvimento da população autóctone, o atual modelo de desenvolvimento rural incorpora a perspectiva de gênero e as pequenas empresas com atividades produtivas alternativas às agrárias. Todos estes elementos resultam na criação de empresas de pequena dimensão que empregam capital e recursos locais. Estes negócios beneficiam a equidade social por proporcionarem ao coletivo feminino uma via de entrada nos mercados laborais rurais, nos quais as perspectiva de emprego são escassas. O compromisso dos empreendedores com o desenvolvimento rural através de iniciativas empresariais está implícito graças à criação de emprego que supõe para a população rural e dos efeitos colaterais que se supõem para os provedores de produtos e serviços do âmbito rural (ROSELL et al. 2006; VAN DER PLOEG, 2000). A aparição destes pequenos negócios ajuda a geração de atividade econômica diversificada e dinâmica, contribui para melhorar a qualidade de vida da população e dinamiza a economia local.

A criação de empresas e o espírito empresarial por parte das mulheres é uma matéria analisada do ponto de diferentes perspectivas desde a década de 80. Na literatura, a comparação entre os dois sexos é feita, geralmente, sem levar em conta o modelo de negócio. A mulher associa-se habitualmente a empresas menores, que crescem mais devagar e são menos rentáveis (FASCI e VALDEZ, 1998; HISRICH e BRUSH, 1984). As diferentes possibilidades que sustentam as diferenças seriam: uma maquiagem psicológica que é menos empresarial ou diferente à de um homem(FAGENSON,1993); menosespíritoempresarial ou menos motivação para o crescimento das suas empresas (FISCHER et al., 1993); não ter experiência ou formação (BODEN e NUCCI, 2000); menos desejo de iniciar um negócio (MATTHEWS e MOSER, 1995); maior aversão ao risco; dificuldades nas aberturas de negócios e mesmo até precisar aulas de formação (NELSON, 1989). Os autores defensores deste estilo de discurso encontram grande parte das suas argumentações em diferenças estatisticamente significativas (mesmo às vezes muito pequenas) sem considerarem as similitudes e coincidências entre os dois sexos (AHL, 2002).

Alguns trabalhos fazem referência, como suporte das diferenças constatadas, a causas alheias às próprias mulheres, evidenciando que existe uma falta de apoio social e cultural da mulher empreendedora. Além disso, defendem a ideia de que as mulheres têm mais problemas para acederem ao capital, como por exemplo, a falta de credibilidade ao tratar com entidades financeiras (HISRICH e BRUSH, 1984).

Porém, alguns trabalhos fazem referência às vantagens para o desenvolvimento dos negócios gerenciados por mulheres, já que estas exibem, muitas vezes, maior habilidade para construir e conservar redes de relações duradouras, maior sensibilidade para necessidades do seu âmbito e para diferenças culturais no campo de ação empresarial (Relatório GEM-2003).

Para as mulheres, o turismo rural representa um dos setores em que teoricamente pode desenvolver-se uma dupla função: uma de cuidado da família e outra de empresária, juntando o trabalho produtivo e o reprodutivo (SAMPEDRO e CAMARERO, 2007).

Sob estas premissas, podemos estabelecer a seguinte hipótese desta pesquisa:

- H1: Existe relação entre gênero e fatores determinantes do comportamento empreendedor.

\subsection{Motivações para empreender atividades de turismo rural, diversificação da atividade agrária e gênero}

Desde a década de 80 , a crise do setor agrário reduziu as oportunidades econômicas das comunidades rurais, forçando o desenvolvimento de estratégias não tradicionais para o sustento das explorações agrícolas. As alternativas de negócio 
que as explorações agrícolas têm são diversas (ILBERY et al., 1998).

Uma das alternativas considerada não tradicional para o desenvolvimento econômico do campo é o turismo associado à oportunidade de negócio. As moradas que combinam atividades agrárias e turísticas entraram no comércio turístico oferecendo, em pequena escala, alojamento de alta qualidade e/ou atividades de desenvolvimento específico para os visitantes. Esta estratégia diversificadora precisa de poucos recursos econômicos, pois é mais fácil a aplicação que outras estratégias de desenvolvimento rural como, por exemplo, a produção agrária em grande escala. É importante também saber que pode ser desenvolvida localmente, com a participação do governo local, através de pequenas empresas, sem precisar de empresas alheias. Oturismo pode gerar importantes rendimentos complementares para as explorações agrícolas, além de proporcionar lucros para as empresas relacionadas diretamente (estabelecimentos que ofertam hospedagem etc.) e as relacionadas indiretamente (postos de gasolina, lojas, restaurantes etc.). A combinação de atividades agrárias e turísticas no rural apresenta-se como uma opção dominante de diversificação desde a década de 90 (ILBERY et al., 1998; POLOVITZ et al., 2001; BARBIERI et al., 2008).

É possível classificar os fatores que influenciam esta diversificação em internos e externos (MCNALLY, 2001). Como fatores internos, refere-se a uma ampla variedade de elementos: tamanho, modelo e antiguidade das explorações, relações de gênero no ambiente familiar, experiências ocupacionais e educativas dos membros da família, sucessão etc. Um fator externo de relevância seria o desenvolvimento de estratégias alternativas nas explorações. Desta maneira, junto à necessidade de incrementar as possibilidades de rendimento e trabalho da exploração agrícola, está o fato de que, muitas vezes, é uma escolha profissional para os herdeiros da mesma. Alguns estudos mostram que as mulheres assinalam mais fatores internos para criar as empresas, enquanto os homens, mais fatores externos (GATEWOOD et al., 1995).
Também se misturam motivos de índole econômica e social (MCGEHEE e KIM, 2004) que podem ser classificados como motivações de racionalidade formal (aquelas estritamente relacionadas com a racionalidade econômica) e as motivações de racionalidade substantiva (aquelas mais além da estrita racionalidade econômica e que guardam relação com a visão de permuta social, com as preocupações morais etc.). Assim, os empresários de turismo rural, além de serem influenciados pela busca de rendimento econômico, também podem manter os trabalhos agrícolas como uma maneira de continuidade das relações familiares, quer pelo interesse nos valores desenvoltos no âmbito agrário, quer pelo interesse em conseguir um vínculo com o mundo urbano sem abandonar o âmbito rural, entre outros fatores.

Além disso, as investigações que analisam em termos gerais as motivações para empreender atividades empresariais e a sua relação com o gênero, revelam que as mulheres podem ter interesses diferentes aos dos proprietários masculinos (BODEN et al., 2000; MARLOW et al., 2009; WATSON e ROBINSON, 2003). Algumas destas motivações podem ser as posições prévias no mercado de trabalho, o conseguimento do equilíbrio de responsabilidades profissionais e pessoais, a satisfação no trabalho, a independência e a autonomia. É por isso que as mulheres podem apresentar preferências menores pela obtenção de resultados econômicos e podem dar início aos seus negócios só por questões de "estilo de vida" (IAKOVIDOU et al., 2009; MARLOW e STRANGE, 1994). Uma análise alternativa das motivações diferencia entre fatores pull ou positivos, derivados do desejo do indivíduo de mudar para uma situação mais atraente, e os fatores negativos ou push, resultantes da necessidade do indivíduo de alterar uma situação que lhe é desagradável, sobrepondo-se à uma situação de insatisfação. As mulheres sofreriam uma combinação de fatores pull e push (MUIR, 1999), tendo em consideração, em muitos casos, o alcance do autoemprego como alvo de crescimento pessoal, como base da decisão de empreender atividades empresariais. 
Diversos estudos, que tratam o tema específico do começo de atividades empresariais de turismo rural e também o empreendimento e o gênero no rural, têm conclusões similares já anteriormente citadas que têm a ver com as diferentes motivações em função do gênero (MCGEHEE e KIM, 2004; IAKOVIDOU et al., 2009, ROBINSO, 2001).

Sob estas premissas podemos estabelecer a segunda hipótese desta pesquisa:

- H2: Existem diferenças significativas entre os gêneros a respeito das motivações para empreender atividades de turismo rural.

\section{Metodologia}

\section{1. Âmbitos de estudo}

A Galiza foi até meados da década de 70 uma comunidade eminentemente agrária, manifestando, desde então, um comportamento no setor agrário que mostra como características mais destacáveis a descida contínua do número de explorações agrárias e a descida do emprego agrário; questões que redundam na perda de peso no setor no conjunto da economia.

$\mathrm{Na}$ Galiza, segundo dados de Contabilidade Regional, a participação do setor agrário no Valor Acrescentado Bruto (VAB) total passou de 12,9\% em 1975 a 6,85\% em 2000 e 2,9\% em 2008. Aliás, constata-se nos últimos anos (IGE, 2010) que o crescimento do VAB agrário não pode seguir o crescimento do VAB total. Paralelamente, o emprego agrário despencou 79,3\% desde 1955 até o ano 2000, sendo no ano 2000 unicamente $14,3 \%$ do emprego total e em 2010, um escasso $2,08 \%$ (IGE, 2010).

Os dados estatísticos de 2010 (IGE, 2010) mostram um mercado laboral na Galiza com 1.15 milhão de trabalhadores, dos quais $54,7 \%$ são homens. O número de trabalhadores que são empresários ascende a 231.1 mil. Considerando como empresários aqueles que contam com operários por conta alheia, apenas o $34,3 \%$ do total são mulheres. A percentagem incrementa-se no caso dos empresários sem trabalhadores, até $41,5 \%$.
Durante a década 2000-2010, o crescimento médio anual de estabelecimentos de turismo rural mantém-se constante em $26,79 \%$. Os dados da oferta de turismo rural na Galiza apresentam a cifra de 587 alojamentos em 2009. Em termos de emprego, são por volta de 900 as pessoas envolvidas em tarefas no setor. A taxa média de número de trabalhadores por estabelecimento é de 1,42 .

A evolução econômica da Galiza desde meados dos anos 70 apresenta a coexistência de dois fenômenos no rural galego: o retrocesso em termos econômicos de atividade agrária e o de uma nova atividade turística. Portanto, é importante analisar em pormenor o comportamento empreendedor neste âmbito e concretamente as suas características em função do gênero para identificar os fatores que determinam a diversificação de atividades no âmbito agrícola.

\subsection{Dados}

Para conhecer as características, o perfil e as motivações dos proprietários e proprietárias de estabelecimentos de turismo rural para empreender atividades turísticas, preparou-se um amplo conjunto de informação, suficientemente representativo, de estabelecimentos de turismo rural da Galícia. Para fazer a seleção das empresas, teve-se como referente o diretório de estabelecimentos de Turismo Rural da Direção Geral de Turismo da Junta da Galícia, que tem 488 estabelecimentos. Para determinar o tamanho do conjunto seguiram-se os procedimentos habituais neste modelo de estudos (população finita, níveis de confiança e limites admissíveis de erro). Com uma margem de erro de $+8 \%$, na hipótese $\mathrm{P}=50 \%$ e nível de confiança de $95 \%$, o tamanho da amostra é de 115. A eleição das empresas do conjunto fez-se aleatoriamente, seguindo a norma UNE 66-010-79 (método que se faz por acaso). Dirigimo-nos pessoalmente às unidades da amostra com o questionário estruturado, combinando previamente por telefone, a entrevista com os proprietários. Período da coleta de dados: janeiro 2009 - maio 2009. 


\subsection{Variáveis e análise}

Observamos como elementos que podem influenciar no comportamento empreendedor aqueles que estejam relacionados de jeito específico com o medio rural no que é desenvolvida a atividade analisada: características pessoais dos proprietários (necessidades de formação, nível educativo, experiência gestora), atividade profissional (distribuição do tempo de trabalho, diversificação de atividades, $\%$ da renda percebida, vinculação à exploração agrária) e características dos estabelecimentos (tamanho, necessidade de recursos para começar o funcionamento).

Para medir a importância das diferentes motivações na decisão de empreender a atividade turística, foi utilizada uma combinação das consideradas por McGehee et al. (2007) com quatro adicionais que figuram em Polovitz et al. (2001). Solicitou-se aos titulares dos estabelecimentos que valorizassem o grau de importância dos seguintes itens sobre uma escala de cinco pontos: temporalidade e flutuação dos mercados agrários; obtenção de rendimentos adicionais; aproveitamento; aproveitamento do nicho de mercado; possibilidade de sucessão futura para a exploração; estilo de vida; possibilidade de emprego no âmbito familiar; possibilidade de abandono da atividade agrária; melhora do uso dos recursos; êxito de outras explorações; conscientização do cliente; hobby; supressão das ajudas no âmbito agrário e aproveitamento das ajudas.

\section{Resultados}

\subsection{Elementos determinantes da iniciativa empresarial e gênero}

Realizamos testes de comparação de médias à procura de diferenças que nos permitam explicar o comportamento empreendedor. Como resultado da aplicação da técnica de análise, achamos relação entre vinculação à exploração agrária e ao gênero. Assim, a compatibilização de atividade turística e agrária é mais forte nos estabelecimentos com propriedade feminina. Igualmente, a renda procedente da atividade agrária tem muita mais importância nos estabelecimentos de mulheres que nos de homens. Reduziu-se, porém, o tempo dedicado a atividades agrárias desde o começo das atividades turísticas. Não se observam importantes diferenças em função do gênero a respeito das variáveis como o tamanho e a iniciativa para criar empresas novas à margem da exploração agrária e das variáveis representativas das características pessoais dos empreendedores.

É por isso que, em relação à primeira das hipóteses propostas no trabalho, podemos estabelecer como elemento distintivo da iniciativa empresarial feminina no turismo rural fatores associados à situação profissional prévia no contexto agrícola, unidos à atividade das explorações agrárias. Não podemos considerar como determinantes outros fatores vinculados ao perfil pessoal da proprietária, como a experiência

Quadro 1. Medidas de características da atividade empreendedora.

\begin{tabular}{|c|c|}
\hline Nome & Medida \\
\hline Nível educativo do proprietário & 0: primária, 1: secundária, 2: universitários \\
\hline Experiência em gestão do proprietário & Escala 0-5 0: nenhuma, 5: muita \\
\hline Horas atuais dedicadas à atividade turística do proprietário & № de horas dedicadas à atividade turística \\
\hline Horas atuais dedicadas à atividade agrária & № de horas diárias dedicadas a trabalho agrícolas \\
\hline $\begin{array}{l}\text { Variação de tempo dedicado à atividade agrária desde } \\
\text { o início da atividade turística }\end{array}$ & $\begin{array}{l}\text { Horas dedicadas antes de começar atividades turísticas menos } \\
\text { horas dedicadas na atualidade }\end{array}$ \\
\hline Vinculação à exploração agrária do proprietário & 1: com vinculação, 0 : sem vinculação \\
\hline Renda atual procedente da atividade agrária & $\%$ da renda total procedente da atividade agrária \\
\hline $\begin{array}{l}\text { Acesso a recursos financeiros/ } \\
\text { endividamento nos começos da atividade }\end{array}$ & $1:<25 \% 2:>25 \%$ e $<50 \% 3:>50 \%$ e $<75 \% 4:>75 \%$ \\
\hline Tamanho do estabelecimento & № de empregados \\
\hline Criação de empresa & 0: não se cria empresa, 1 : sim, se cria empresa \\
\hline
\end{tabular}


em gestão ou o nível educativo. Também não podemos estabelecer relação nem com o tamanho dos estabelecimentos nem com as necessidades financeiras prévias para empreender.

\subsection{Análise das motivações para empreender atividades turísticas no rural, diversificação e gênero}

Tendo em consideração o conjunto de motivações analisado em pesquisas anteriores sobre turismo rural, analisamos possíveis diferenças significativas nas decisões das pessoas proprietárias dos estabelecimentos de turismo rural em função do gênero. É por isso que realizamos uma comparação de médias para os estabelecimentos que têm propriedade masculina e para os estabelecimentos que têm propriedade feminina.

De uma parte, observamos que os motivos que podemos classificar como estritamente econômicos têm maior importância para as mulheres doque para os homens. Portanto, os valores médios de todas estas motivações são superiores aos dos homens. Além disso, a principal motivação para as mulheres é a obtenção de rendimentos adicionais. Estatisticamente, observam-se diferenças significativas entre os valores médios, tanto no aproveitamento do nicho de mercado quanto na situação dos mercados agrários e a melhora do uso dos recursos econômicos. Este resultado está em concordância com o de outros estudos que analisaram os motivos da diversificação no rural (MCGEHEE e KIM, 2004; MCCOOL e MOISERY, 2001; ILBERY et al., 1998; REIJONEN e KOMPPULA, 2007). É por isso que descobrimos na geração de rendas que asseguram a sobrevivência financeira um motivo dominante para as mulheres.

A realização de novas atividades para assegurar a futura continuidade das atividades agrárias, o conseguimento de emprego para membros da família, a escolha sobre o estilo de vida (independência, sociabilidade com clientes etc.) ou fatores institucionais não são considerados mais relevantes para as mulheres do que para os homens.

Estas ilações são contrárias ás conseguidas na literatura que mostra menor preferência das mulheres pelos resultados estritamente econômicos e mais por motivações não econômicas (IAKOVIDOU et al., 2009; MARLOW e STRANGE, 1994; RUANE e SUTHERLAND, 2007). Outros estudos específicos de empreendedorismo no rural indicam ainda uma maior preferência causada por motivos não relacionados com aspetos econômicos (MCGEHEE et al., 2007; IAKOVIDOU et al., 2009, ROBINSON, 2001). Pelo contrário, descobrimos resultados que indicam que muitos destes propósitos têm uma

Tabela 1. Comparação de valores médios de variáveis conforme o gênero.

\begin{tabular}{|c|c|c|c|c|c|c|}
\hline \multirow[b]{2}{*}{ Características empreendedores } & \multicolumn{2}{|c|}{ Homens } & \multicolumn{2}{|c|}{ Mulheres } & \multirow[b]{2}{*}{ Ftest } & \multirow[b]{2}{*}{ Significância } \\
\hline & Média & $\begin{array}{l}\text { Desvio } \\
\text { Padrão }\end{array}$ & Média & $\begin{array}{l}\text { Desvio } \\
\text { Padrão }\end{array}$ & & \\
\hline Nível educativo & 1,13 & ,757 & 1,14 & ,782 & 200 & 656 \\
\hline Experiência em gestão & 47 &, 505 &, 55 &, 502 & ,123 & ,172 \\
\hline Horas dedicadas à atividade turística & 11,2 & 2,3 & 11,6 & 3,5 & 1,42 & 235 \\
\hline Horas dedicadas à atividade agrária do proprietário & 1,68 & ,32 & 1,58 & 11 &, 515 & 474 \\
\hline $\begin{array}{l}\text { Variação de tempo dedicado à atividade agrária } \\
\text { desde o início da atividade turística }\end{array}$ & 1,48 & 62 & 2,28 &, 7 & 4,722 &, $032^{* *}$ \\
\hline Vinculação à exploração agrária & 0,17 & 0,38 & 0,30 & 0,43 & 9,874 &, $002^{* * *}$ \\
\hline Renda procedente da atividade agrária & 4,78 & 16,2 & 14,5 & 28,5 & 14,5 &, $000^{* * *}$ \\
\hline $\begin{array}{l}\text { Acesso a recursos financeiros/ } \\
\text { Nível de endividamento nos começos da atividade }\end{array}$ & 1,98 & 1,3 & 1,52 & 1,4 & ,700 & 405 \\
\hline Tamanho & 11,85 & 4,25 & 12,68 & 5,26 & 1,454 & 231 \\
\hline Criação de empresas & ,2391 &, 012 & 2667 &, 065 &, 415 &, 521 \\
\hline
\end{tabular}

Fonte: **indica significância estatística a 5\% . ${ }^{* * *}$ indica significância estatística a $1 \%$.

Fonte: Elaborado pelas autoras a partir dos dados da pesquisa de campo. 
importância similar para homens e mulheres. Não podemos defender que a iniciativa empresarial feminina cumpra uma função de realização pessoal sobre qualquer outra função, mas, sim, que o sentido da mesma reside em primeiro lugar numa função econômica.

É por isso que em relação à segunda das hipóteses propostas, constatamos que existe relação entre as motivações para empreender a atividade empresarial de turismo rural e o gênero, sendo mais importantes as motivações econômicas para as mulheres do que para os homens.

\section{Ilações, limitações e futuras linhas de pesquisa}

Neste trabalho foram analisadas as diferenças em função do gênero no comportamento empreendedor no setor do turismo rural. As variáveis comparadas são os fatores determinantes e as motivações para empreender.

Achamos, nos fatores determinantes, elementos que apontam para uma predisposição das mulheres na diversificação da atividade agrária para a turística (nos estabelecimentos dirigidos por mulheres é ampla a tendência a vincular atividade turística e agrária e é superior a percentagem de renda procedente da atividade agrária). Essa ampla tendência feminina a diversificar é paralela ao fato de as mulheres aumentarem significativamente o tempo que destinam à nova atividade turística frente à inicial atividade agrária. É por isso que estes dados apontam para uma maior profissionalização e implicação empresarial das mulheres com os projetos turísticos criados por elas.

A respeito da análise das motivações para empreender atividades turísticas, observamos que as motivações econômicas apresentam importantes diferenças em função do gênero (os elementos econômicos são mais valorizados no caso dos estabelecimentos com propriedade feminina). Assim, as mulheres empreendem atividades turísticas com a decidida intenção de obter rendimento econômico e com um decidido propósito econômico. As possibilidades econômicas das proprietárias são mais fortes do que as dos proprietários. Esta ilação é contraria à da literatura que defende a prioridade de objetivos do âmbito social ou familiar frente os objetivos econômicos (IAKOVIDOU et al., 2009; MARLOW e STRANGE, 1994). Em um setor como o do turismo rural, onde aparecem características incentivadoras tradicionais para o desenvolvimento da atividade empresarial feminina, as mulheres consideram como elementos motivadores mais destacados os econômicos, ao contrário do que acontece com os homens.

Tabela 2. Motivações para empreender conforme o gênero. Média e diferenças significativas.

\begin{tabular}{|c|c|c|c|c|c|}
\hline & Motivações para empreender & Homens & Mulheres & Ttest & Significância \\
\hline \multirow{4}{*}{ Econômicas } & Obtenção de rendimentos adicionais aos agrários & 3,10 & 3,56 & 117 & ,736 \\
\hline & Situação dos mercados agrários & 2,30 & 2,50 & 4,3 &, $049^{* *}$ \\
\hline & Aproveitamento do nicho de mercado & 2,60 & 3,13 & 5,627 &, $026^{* *}$ \\
\hline & Melhora do uso dos recursos econômicos & 3,50 & 3,25 & 5,739 &, $025^{* *}$ \\
\hline \multirow{7}{*}{ Sociais } & Possibilidade de emprego no âmbito familiar & 3,50 & 2,44 & 1,251 & 274 \\
\hline & Estilo de vida & 3 & 3,19 &, 001 & ,970 \\
\hline & Abandono da atividade agrária & 2,50 & 2,06 &, 040 & 844 \\
\hline & Sucessão futura para a exploração & 3,70 & 3,06 & 1,897 & ,181 \\
\hline & Sucesso de outras explorações & 2,40 & 1,94 & 139 & ,712 \\
\hline & Conscientização do cliente & 2,20 & 2,00 & 8,505 &, 564 \\
\hline & Hobby & 1,70 & 1,94 &, 527 & 475 \\
\hline \multirow{2}{*}{ Institucionais } & Supressão das ajudas agrárias & 2,40 & 1,75 & ,014 & 907 \\
\hline & Aproveitamento das ajudas & 2,30 & 2,81 &, 002 & ,967 \\
\hline
\end{tabular}

**indica significância estatística a 5\%.

Fonte: Elaborado pelos autores a partir dos dados da pesquisa de campo. 
As mulheres, muito mais do que os homens, respondem aos habituais motivos de diversificação produtiva no rural (MCGEHEE e KIM, 2004; MCCOOL e MOISERY, 2001; ILBERY et al., 1998; REIJONEN e KOMPPULA, 2007): a geração de rendas que garanta a sobrevivência financeira.

É o nosso desejo, neste estudo, continuar analisando a situação da mulher no turismo rural e as possíveis relações causais entre gênero e variáveis de gerência. Seria de interesse introduzir a distinção entre gerência e propriedade no momento de contemplar a variável gênero. Poderíamos avançar na pesquisa diferenciando as diversas classes de empreendedoras, como as criadoras de autoemprego, as geradoras de rendimentos adicionais (normalmente a tempo parcial) e as que podem considerar-se estritamente como empresárias. Também é interessante compilar informação ao longo do tempo para estudar possíveis diferenças nas possibilidades de sobrevivência e crescimento das empresas no longo prazo. As características do contexto geográfico em que foi realizado o estudo empírico podem condicionar os resultados obtidos. Trasladar o campo de análise a outros âmbitos territoriais ou a outros setores influenciaria na detecção de diferenças ou de similitudes nos resultados.

Do mesmo jeito, outras técnicas estatísticas permitiriam novos contrastes de hipóteses.

\section{Referências bibliográficas}

AHL, $\mathrm{H}$. The construction of the female entrepreneur as the other. In: Czarniawska B. e Höpfl H. (Eds.), Casting the Other. The production and maintenance of inequalities in work organizations. pp. 52-67. London: Routledge. 2002.

ANTÓN, S., LÓPEZ, F., MARCHENA, M. e VERA, J. F. La investigación turística en España: aportaciones de la geografía (1960-1995), Estudios turísticos, № 129, p. 165208. 1996.

BAKER, T., ALDRICH, H. E. e LIOU, N. "Invisible entrepreneurs: The neglect of women business owners by mass media and scholarly journals in the USA", Entrepreneurship \& Regional Development, №9, p. 221-238. 1997.

BARBIERI, C. e MSHENGA, P. The role of firm and owner characteristics on the performance of agritourism firms, Sociologia ruralis, Vol. 48, № 2. 2008.
BIGNE, E. Turismo y marketing, Una revisión y perspectivas de futuro, Estudios Turísticos, № 129, p. 105-127. 1996.

BODEN, R. J. e NUCCI, A. R. On the survival prospects of men's and women's new business ventures, Journal of Business Venturing, 3 (4), pp. 347-362. 2000.

BRULLET, C. Infancias y familias: realidades y tendencias, Ariel, Barcelona. 2004.

BRUSH, C. G., CARTER, N. M., GATEWOOD, E. J., GREENE, P. G. e HART, M. (Eds.). Growth-oriented women entrepreneurs and their businesses: A global perspective. Cheltenham, U. K.: Edward Elgar. 2006.

CABALLÉ, A. Farm tourism in Spain: a gender perspective, Geojournal, № 48, pp. 245-252. 1999.

CANOVES, G. e VILLARINO, M. Rural tourism, gender and landscape conservation in Spain and Portugal. In Swaim M.; Momsen J.(Eds.), Gender, tourism and fun, pp. 90-108: Coignizant Press. 2002.

ESTEBAN, A. La investigación turística en la universidad española, Estudios turísticos, № 144-145, pp. 155-180. 2000.

FAGENSON, E. A., Personal value system of men and women entrepreneurs versus managers, Journal of Business Venturing, №8, pp. 409-430. 1993.

FASCI, M. A. e VALDEZ, J. A performance contrast of male- and female-owned small accounting practices, Journal of Small Business Management, 36(3), pp. 1-7. 1998.

FIGUEROLA, M. Los trabajos de investigación de la economía del turismo en el Instituto de Estudios Turísticos (1974-1993), Estudios turísticos, № 144-145, pp. 17-45. 2000.

FISCHER, E. M., REUBER, R. A. e DYKE, L. S. "A theoretical overview and extension of research on sex, gender and entrepreneurship", Journal of Business Venturing, 8 (2) 151-168. 1993.

GARCÍA RAMÓN, M. D., CÀNOVES, G., SALAMAÑA, I., VALDOVINOS, N., GATEWOOD E., SHAVER Y K. e GARTNER, W. B. A longitudinal study of cognitive factors influencing star-up behaviours and success at venture creation, Journal of Business Venturing, 10 (5), pp. 371-391. 1995.

HISRICH, R. D. e BRUSH, C. The woman entrepreneur: Management skills and business problems, Journal of Small Business Management, 22(1), pp. 30-37. 1984.

IAKOVIDOU. O., KOUTSOU, S. e PARTALIDOU, M. Women entrepreneurs in the greek countryside: a typology according to motives and business 
characteristics, Journal of Development Entrepreneurship, Vol. 14, № 2, 169: Routledge. 2009.

ILBERY, B., BOWLER, I., CLARCK, G., CROCKETT, A. e SHAW, A. Farm-based tourism as a alternative farm enterprise: A case study from the Northern Pennines, England, Regional Studies, vol. 32, pp. 355-364. 1998.

INSTITUTO GALEGO DE ESTATÍSTICA (IGE): http:// www.ige.eu

LITTLE J. "Gender Relations in Rural Areas: the importance of women's domestic role", Journal of rural studies, Vol. 3, № 4, pp. 335-342. 1987.

MARLOW, S., HENRY, C. e CARTER, S. Introduction: Female Entrepreneurship, Special Edition, International Small Business Journal, 27 (2) pp.1-9. 2009.

MARLOW, S. e STRANGE, S. Female entrepreneurs: Success by whose standards?, en Taton, M. (ed).: Women in Management Developing Presence, London. 1994.

MARTÍNEZ E. Mujeres emprendedoras en el desarrollo rural. Atlas regional de España de la participación de las mujeres rurales emprendedoras en la Iniciativa Comunitaria LEADER II, Estudios e investigaciones, MTAS. Instituto de la Mujer. 2007.

MATTHEWS, C. H. Y. e MOSER, S. B. Family background and gender: implications for interest in small firm ownership, Entrepreneurship \& Regional Development, 7: p. 365-377. 1995.

MCCOOL, S. e MOISERY N. Tourism Recreation and Sustainability: Linking Culture and the Environment, CABI Publishing. 2001.

MCGEHEE, N. e KIM, K. Motivation for agri-tourism entrepreneurship, Journal of Travel Research, Vol. 43, pp. 161-170. 2004.

MCGEHEE, N., KIM, K. e JENNINGS, G. Gender and motivation for agri-tourism entrepreneurship, Tourism Management, Vol. 28, № 1, pp. 280-289. 2007.

MCNALLY, S. Farm diversification in England and Wales - what can we learn from the farm business survey?, Journal of Rural Studies, № 17, pp. 247-257. 2001.

MUIR, E. J. Woman entrepreneurs in the EU: motivations and realisations for starting a Business, comunicacion presentada en el ICBS, 1999, Napoles, Junio. 1999.

NELSON, G. Factors of friendship: relevance of significant others to female business owners, Entrepreneurship Theory and Practice, 13 (4), pp. 7-18. 1989.

POLOVITZ, N., BLACK, R. e MCCOOL, S. Agrotourism: motivations behind farm/ranch business diversification; Journal of Travel Research, Vol. 40, pp. 1926. 2001.

REIJONEN H. e KOMPPULA R. Perception of success and its effect on small firm performance, Journal of Small Business and Enterprise Development, Vol. 14, № 4, pp. 689-701. 2007.

ROBINSON, S. An examination of entrepreneurial motives and their influence on the way rural women small business owners manage their employees, Journal of Development Entrepreneurship, Vol 6, № 2, pp. 151-167. 2001.

ROSSELL, J., VAILLANT, Y. e VILADOMIU, L. Apoyo a las empresas y empresarios rurales em Cataluña, Revista de Estudios Regionales, pp.156-178. 2006.

RUANE, F. e SUTHERLAND, J. Firm performance characteristics and gender ownership in a globalised Economy, IIIS Discussion Paper, no 200, Institute for International Integration Studies. 2007.

SAMPEDRO, R. e CAMARERO L. Mujeres empresarias en el mundo rural. El sujeto pendiente de desarrollo, Revista Internacional de Sociología, Vol 65 № 48, pp. 121-146. 2007.

SPARRER, M. Género y turismo rural. El ejemplo de la costa coruñesa, en: Cuadernos de Turismo, № 11, Universidad de Murcia, Murcia, pp. 181-197. 2003.

SPARRER, M. Turismo no espazo rural e desenvolvementoEstudo comparativo da provincia da Coruña e o Landkreis Wittmund. Xunta de Galicia. Direccion Xeral de turismo. 2005.

VAN DER PLOEG D. J., RENTING, H., BRUNORI, G., KNICKEL, K., MANNION, J., MARSDEN, T., SEVILLA GUZMAN, E. e VENTURA, F. "Rural Development: from practices and policies towards theory", Sociologia ruralis, Vol.40, № 4, pp. 391-408. 2000.

VERHEUL, I., VAN STEL, A. e THURIK, R. Explaining female and male entrepreneurship across 29 countries SCALES, paper no 200403. 2004.

VILLARINO, M. Trabajo de la mujer, turismo rural y percepción del entorno: una comparación entre Cataluña y Galicia, Agricultura y sociedad (75), pp. 115-152. 1995.

WATSON, J. e ROBINSON, S. Adjusting for risk in comparing in comparing the performance of male and female controlled SME, Journal of Business Venturing, Vol. 18, № 6, pp. 773-788. 2003.

WILSON, S., FESENMAIER, D., FESENMAIER, J. e VAN ES, J. Factors for Success in Rural Tourism Development, Journal of Travel Research, vol. 40, pp. 132-138. 2001. 